\title{
Rural restructuring and gendered micro-dynamics of the agricultural labour market
}

\author{
MARTIN HEDLUND, LINDA LUNDMARK AND OLOF STJERNSTRÖM
}

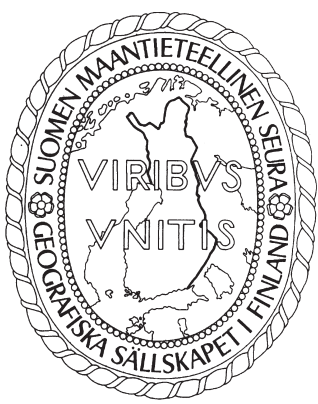

Hedlund, Martin, Linda Lundmark \& Olof Stjernström (2017). Rural restructuring and gendered micro-dynamics of the agricultural labour market. Fennia 195: 1, pp. 25-35. ISSN 1798-5617.

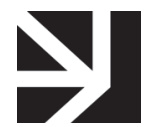

Based on a comparison of the employment trajectories of two cohorts of men and women in the agricultural sector in Sweden, this article gives an account of the past 50 years' decline in employment in agriculture. The findings show that the decline of employment in agriculture was the result of fewer entries into the sector and more exits out of the sector. The findings also suggest that the restructuring of the agricultural sector has had greater effects on women than men, with women exiting the sector to a greater degree or never entering it to begin with.

Keywords: agricultural decline, rural restructuring, off-farm employment, lifecourse perspective, Sweden

Martin Hedlund, Linda Lundmark \& Olof Stjernstöm, Department of Geography and Economic History, Umeå University, Universitetstorget 4, 90187, Umeå, Sweden. E-mails: martin.hedlund@umu.se, linda.lundmark@umu.se, olof. stjernstrom@umu.se

\section{Introduction}

Employment in agriculture has declined steadily across the developed world, not least in the Nordic countries, during the post-World War II era. In Sweden, rural areas have been experiencing a gradual depopulation for several decades, which to some extent is related to industrial innovations within agriculture and rural industry in the post-war era (Flygare \& Isacson 2003). Structural change induced by innovations in production has resulted in more specialized firms (Sæther 2010), but has also meant that farm output has grown without creating new jobs (Almstedt et al. 2014). In a Swedish context, this has not necessarily meant a consolidation of farms into what has been termed super-production and thus a contradiction to multi-functionality; instead, a more small-scale agriculture has become the norm for hyper-production in this context (Almstedt et al. 2014). The driving force behind this development can be found in the interplay between technological and organizational innovations and policy decisions (Flygare \& Isacson 2003; Sæther 2010), and is also one of the reasons behind the current process of rural restructuring. Thus, once the backbone of rural societies, agriculture has now become less important for employment in contemporary rural areas in general (Woods 2005; OECD 2006), but also in the case discussed here.

A large body of literature has theorized and investigated the reasons behind agricultural decline and its implications for rural regions (Ilbery 1998; Evans et al. 2002). The literature on recent rural restructuring describes a changing labour market, going from a focus on natural resources to services (Shaw \& Williams 1994; Woods 2005; OECD 2006). In public policy, the inclination has been to reshape rural places towards the new economy (Woods 2010) by focusing on service instead of primary production. In brief, the new economy, defined by this shift of economic focus, also entails a shift in labour market 
dynamics and mobility patterns into labour markets with high levels of mobility within and between sectors and regions (Lundmark et al. 2014). Previous agricultural restructuring has been attributed to innovation, rationalization and more effective practices within the farm itself, rather than being part of an economic shift that changes the composition of the rural labour market in its foundations.

The aim of this study is to investigate how the labour market trajectories for men and women working in the Swedish agricultural sector were affected by the structural changes in the agricultural labour market described above. Of special interest are changes in labour market dynamics for individuals working in agriculture during this period of intensification and rationalization within the Swedish agricultural sector. The transformation of the agricultural sector in developed countries has meant that the number of farmers has decreased, and that the share of the population working in agriculture is smaller (Woods 2005). However, previous quantitative studies have mostly focused on how employment in agriculture has changed on the aggregate level, whilst less is known about changes on the individual level (Troughton 1986; Ilbery \& Bowler 1998; Parson 1999). In order to investigate individual-level changes, this paper applies a life-course perspective on the men and women working in agriculture. By following the work trajectories of individuals rather than the stock of agricultural workers, it is possible to observe exits from and entries into the sector, as well as which sectors individuals exited or entered. Compared with the more common cross-sectional method, this approach gives more information on how employment in agriculture declined from the perspective of the individual. Furthermore, with the individual rather than the sector as a vantage point, it is possible to capture how agricultural employment is related to the larger labour market. Empirically, this task is undertaken by comparing employment trajectories between two cohorts of agricultural workers, the first born in 1938-1940 and the second in 1958-1960.

The possibility/incitement for individuals to continue to work in agriculture is dependent on changes within the sector itself, but also on changes within the labour market in general, creating a dynamic network between agriculture and other economic mainstays. An increasingly competitive environment due to new technology and globalizing markets should mean that it has become harder economically to continue to work in the agricultural sector (Flygare \& Isacson 2003). Furthermore, several studies show that the conditions for agricultural workers are different for women. For example, in farmer households it is much more common for the women to engage in off-farm employment should it be needed for the household economy (Ember 1983; Buttel \& Gillespie 1984; Rosenfeld 1985). Another important question is therefore whether there is a gender difference in the changes in the agricultural labour dynamics.

Specific research questions are: 1) To what extent did exits from agriculture differ between the 1940 and 1960 cohorts, and between men and women?; 2) Which sectors of employment did those who exited agriculture enter? Was there a difference between the cohorts and sexes?; and 3) To what extent did re-entry into agriculture differ between cohorts, between sexes, and between previous sectors of employment?

Answering the above questions gives a picture of the labour-market dynamics involved in the decline of agricultural employment in Sweden. However, there are similarities between Sweden and other developed countries when it comes to agricultural change. The mechanization and the rise of productivist agriculture has led to a decrease in agricultural employment all over the developed world (Woods 2005). Between 1983 and 2003 employment in agriculture decreased by 30\% or more in most OECD countries, and in 2003 the share of total employment in agriculture was less than 5\% in the majority of OECD countries (OECD 2006). Whilst the Swedish agricultural sector and the general Swedish labour market has its distinct particularities (not least due to the cold climate) there are reasons to believe that this study can shed some light on the dynamics of agricultural decline in other countries as well.

\section{Structural changes on the rural labour market in Sweden}

The literature on rural restructuring describes a labour market transformation from natural resources to services (Shaw \& Williams 1994; Woods 2005; OECD 2006). The structural change in rural areas, like development in urban areas, is strongly related to the development of various economic activities. Economic change is not to be viewed as an isolated process, but is rather interlinked with other change 
in society. How they are linked together, and under what circumstances, is not always straightforward to uncover, and understanding the structure and the causality between different parameters and results is complex (Hoggart \& Paniagua 2001).

Rural restructuring can be theorized and investigated in many ways, but the main part of research focuses on aggregated change. One strand of research focuses on social and economic changes within the agricultural sector (Ilbery \& Bowler 1998; Shucksmith \& Herrmann 2002; Woods 2005), and another on social and economic restructuring on a local or regional level (Pettersson 2002; Hedlund \& Lundholm 2015), departing from a geographical rather than a sectorial perspective. One main strand of research representing the latter approach focuses on population development in rural areas, including colonization, urbanization, depopulation, ageing populations, et cetera (Boyle \& Halfacree 1998; Woods 2010). The problematization of depopulation in rural areas relates to economic restructuring, urbanization and technological development. The specialization and modernization of the agricultural sector started earlier than industrialization, and restructuring processes in the agricultural sector served as a pre-condition for the industrialization process. Whilst the agricultural restructuring in the 20th century has continued to impact population density, population composition and urbanization, the extensive nature-based sectors, such as agriculture and forestry, still characterize many rural areas today, and the production capacity measured as production per workhour has increased many times over (Almstedt et al. 2014).

The literature discussing agricultural change normally identifies, or refers to, the three waves of agricultural revolution: the prehistoric domestication of crops and animals; commercial modes of production; and the ongoing process of agricultural industrialization (Troughton 1986; Parson 1999). Many studies of agricultural change depart from capitalization and the substitution of capital for labour (Parson 1999). The globalization of agricultural production and the internationalization of the food market is another central theme (Friedmann \& McMichael 1989; Alston \& Pardey 2014). These macro changes have affected the local production conditions, and the agricultural intensification of production has resulted in, among many other things, not only off-farm input such as labour, machinery, technology, et cetera, but also rationalization and the need for off-farm employment. The agricultural sector has developed from traditional family-based farming into production for a wider (global) market since World War II (Parson 1999; Lobao \& Meyer 2001).

Women's role in the restructuring process is somewhat hidden, according to Lobao and Meyer (2001). To some extent, this problem emanates from how historical register data include the women on a family farm. However, it is rather well known that there is a clear gendered division of labour on family farms (Rosenfeld 1985; Lasley et al. 1995; Barlett et al. 1999). The institutionalization of welfare production, for instance in the Swedish case, has resulted in off-farm employment for many women in relation to traditional family farming. An important condition in the transformation of the agricultural sector involves property rights and gender. In small-scale farm production, farm properties were mostly owned by men and transferred to men after retirement (Dribe \& Lundh 2005). This might have had an impact on the institutionalization of household work and the growth of the public sector and welfare institutions. This process also contributed to creating a labour market accessible to women lacking previous labour market experience. Another dimension of the changes towards service entails that the 'new' labour market opens up opportunities for women in rural areas that were not previously available, which is currently regarded as presenting the possibility to retain the female workforce in rural areas (Hedlund \& Lundholm 2015).

'Multifunctionality', as described by McCarthy (2005: 773-774), is "the idea that rural landscapes typically produce a range of commodity and non-commodity use values simultaneously and that policy ought to recognize and protect that entire range of values". As a concept, multifunctionality “... encapsulates the diversity, non-linearity and spatial heterogeneity" in rural society (Wilson 2001: 96). However, the novelty of multifunctional rural areas can be questioned as being ahistorical, since it seems to forget a long history of highly diverse activities in rural areas before the productivist era (Müller 2010; Vepsäläinen \& Pitkänen 2010). Wilson (2001) sets out multifunctionality as trajectories along which individual farm businesses move, ranging between the productive and the non-productive. Multifunctionality, whilst having relevance at the individual farm-unit level, has far greater potential at the regional and national levels. 
For economic sectors in decline or in the process of rationalization, national and supra-national policies could have great influence through, for instance, subsidies and other public or state financial support. In their study of Kansas farmers, Mishra and Goodwin (1997) show that policy changes have an effect on off-farm employment. An alternative meaning of the importance of women in off-farm employment is shown by Kelly and Shortall (2002). In their study of Irish family farms, they show that women with off-farm employment could serve as farm-supportive breadwinners in times of transformation or economic hardship. Family farms looking for alternative or complimentary incomes could apply different strategies, of which off-farm employment is one and external subsidies or investments might be another. Off-farm employment and investments are linked to the individual farm, whereas external subsidies make the farm dependent on the development of agricultural policies. In recent years, public policy has become increasingly oriented towards supporting other economic activity than agriculture in rural areas (Almstedt et al. 2015).

Previous research has shown that men and women have held different roles on the family farm, with men often having the most influence over the business. Due to rationalization, it was therefore often the women who left agriculture for other job opportunities. Based on such research, it is reasonable to believe that the agricultural restructuring has had different implications for men and women.

\section{Method and data}

The data used in this study consist of a combination of census and register data on the entire Swedish population between 1960 and 2010 at five-year intervals. The census data cover the period 19601990, and the register data 1990-2010. Among other variables, the data sources contain information on employment, year of birth, gender, income and parish of residence, which were the variables used in this study. The data was extracted from the ASTRID-database which is located at the Department of Geography and Economic History at Umeå University. The data in ASTRID stems from a combination of census data (1960-1990) and annual registers (1985-2010) at Statistics Sweden. In Sweden, researchers may be granted access to longitudinal, but anonymized, census and register data as long as certain conditions are fulfilled.

For the purpose of this study, the data were prepared in two steps. In the first step, two cohort groups of agricultural workers were selected: the first born between 1938 and 1940, and the second born between 1958 and 1960. In order to qualify into one of the groups, the individuals in the specified cohorts also had to have worked in agriculture when they were 20 and 25 years old, respectively. This resulted in a cohort group born in 1938-1940' of 3,893 agricultural workers (3140 men and 753 women), and a cohort group born in 1958-1960² of 2,184 agricultural workers (1824 men and 360 women). In the second step, a status variable was created showing which sector the individual worked in, or that the individual was not working. The sector in which the individual worked was based on a four-digit sectorial code aggregated into five broader sectors: agriculture, other natural resource, manufacturing, service, and public.

When the groups had been selected and the status variable defined, the work-life trajectories of the cohort groups were analysed by gender. The employment status of the agricultural workers was measured each five years, starting at age 30-32 and ending at age 50-52 (at ages 20-22 and 25-27, all selected individuals worked in agriculture). The data analysis consisted of comparing the relative changes of the work-life trajectories between the cohorts and between genders. This analysis was conducted with the help of descriptive graphs and tables from the sequence analysis R-package TraMineR (Gabadinho et al. 2011).

The empirical part of this study contains one significant limitation related to the data sources. The data only contain one employment code per individual and year, even though some individuals held more than one job; only the job from which the individual received the highest salary during the year is listed. This means that the study is unable to capture off-farm work, which is a fairly common practice amongst farmers, especially women. Thus, part-time work off the farm is displayed as an exit from agriculture in cases in which the income from the off-farm work is larger than that from agriculture. In the cases in which the income from agriculture is larger than that from the off-farm work, the data holds no information on any off-farm work. 


\section{Micro-dynamics of employment in the Swedish agricultural sector}

In order to investigate the changes in employment trajectories of agricultural workers in Sweden, the analysis begins with the data for the men's cohorts and then moves over to the women's cohorts (Table 1, 2; Fig. 1). As a second step, the intra--individual change in income from switching to another sector was compared between the cohorts in order to investigate the extent to which it was more difficult to remain in agriculture in the 1960 cohort (Table 1, 2).

Table 1 shows the average rate of transition between the sectors for each cohort. The rows show average transition rate from sector and the columns show average transition rate into sector five years later. For example, the figure $24 \%$ in the second row of the first column means that $24 \%$ on average of the male cohort 1940 who worked in natural resource sectors worked in agriculture five years later. Table 2 shows the share of the cohorts who worked in each sector (or were not working) between age 30 and age 50. Age 20 and 25 is omitted from the table since all individuals, by selection, worked in agriculture at those ages.

Table 1. Average transition rates between sectors by cohort and sex in percentage ( $A=$ agriculture, NR = natural resources, $\mathrm{M}=$ manufacturing, $\mathrm{S}=$ services, $\mathrm{P}=$ public, $\mathrm{NW}=$ not working).

\begin{tabular}{|c|c|c|c|c|c|c|c|c|c|c|c|c|c|}
\hline & & \multicolumn{2}{|c|}{ A } & \multicolumn{2}{|c|}{ NR } & \multicolumn{2}{|c|}{$M$} & \multicolumn{2}{|c|}{$P$} & \multicolumn{2}{|c|}{$S$} & \multicolumn{2}{|c|}{ NW } \\
\hline & Sector/Cohort & 1940 & 1960 & 1940 & 1960 & 1940 & 1960 & 1940 & 1960 & 1940 & 1960 & 1940 & 1960 \\
\hline \multirow{6}{*}{$\frac{\bar{d}}{\sum}$} & $A$ & 86 & 83 & 3 & 3 & 4 & 3 & 1 & 1 & 4 & 6 & 2 & 4 \\
\hline & NR & 24 & 23 & 50 & 56 & 9 & 5 & 2 & 1 & 11 & 10 & 3 & 5 \\
\hline & $M$ & 7 & 7 & 3 & 3 & 76 & 72 & 1 & 1 & 10 & 13 & 3 & 4 \\
\hline & $P$ & 8 & 10 & 5 & 3 & 5 & 1 & 70 & 71 & 10 & 11 & 2 & 5 \\
\hline & $S$ & 10 & 8 & 4 & 3 & 8 & 4 & 2 & 2 & 74 & 77 & 3 & 5 \\
\hline & NW & 16 & 33 & 5 & 6 & 9 & 5 & 2 & 4 & 9 & 11 & 59 & 41 \\
\hline \multirow{6}{*}{ 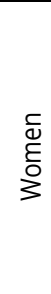 } & $A$ & 74 & 83 & 1 & 3 & 1 & 3 & 4 & 1 & 3 & 6 & 16 & 4 \\
\hline & NR & 20 & 23 & 41 & 56 & 0 & 5 & 17 & 1 & 7 & 10 & 15 & 5 \\
\hline & $M$ & 1 & 7 & 1 & 3 & 75 & 72 & 8 & 1 & 8 & 18 & 7 & 4 \\
\hline & $P$ & 5 & 10 & 0 & 3 & 3 & 1 & 79 & 71 & 5 & 5 & 8 & 5 \\
\hline & $\mathrm{s}$ & 9 & 8 & 1 & 3 & 4 & 4 & 12 & 2 & 65 & 69 & 9 & 5 \\
\hline & NW & 31 & 33 & 2 & 6 & 4 & 5 & 13 & 4 & 8 & 10 & 42 & 41 \\
\hline
\end{tabular}

Figure 1 is a sequence index plot of all the cohorts. The individuals in each cohort are distributed along the $y$-axis, where the whole $y$-axis comprises $100 \%$ of the individuals in the cohort, and the $\mathrm{x}$-axis is a temporal axis. Each pixel-row in the figure thus shows the employment trajectory of one or several individuals measured with a five-year interval, starting at age 20 and ending at age 50, for each cohort. The individuals in the figure have been sorted based on a clustering-technique included in the TraMineR-package.

\section{Men in agriculture}

At age 30 in the men's 1940 cohort, $27 \%$ of men had exited agriculture, with most of them going into services (10\%) and manufacturing (8\%). A slightly smaller share of them (6\%) started working in other natural resource sectors such as forestry, gardening and mining, and only a tiny share of 


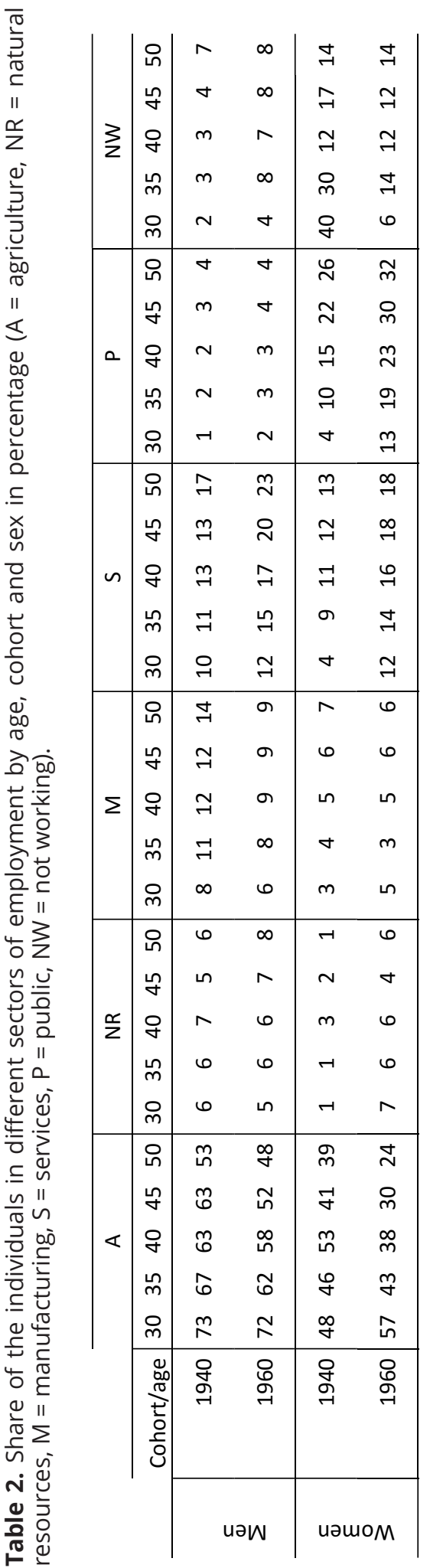

the men started working in the public sector (1\%) or became unemployed (2\%). As the individuals grew older employment in agriculture continued to decrease: by age $40,63 \%$ of the men worked in agriculture, and by age 50 employment in agriculture had decreased to $53 \%$ of the cohort. It was mainly employment in manufacturing and services that increased, whilst the public sector only increased slightly and other natural resource sectors stagnated. The share who did not work also increased slightly, to $3 \%$ of the men at age 40 and $7 \%$ at age 50 .

Table 1 shows the average share of individuals who remained in or switched from one sector into another for every five years between ages 30 and 50 . In the men's 1940 cohort, $86 \%$ of those who worked in agriculture still did so five years later, whilst $12 \%$ of them had switched to another sector and $2 \%$ were not working. Once in another sector, approximately 75\% of the men's 1940 cohort were still in that sector five years later, with the exception of other natural resource sectors, where only half remained five years later. Other natural resource sectors were less stable than the others, with $24 \%$ of the men having returned to agriculture five years later; this reflects the fact that this sector is more closely related to agriculture than the others are.

The top left diagram in Figure 1 summarizes the information above. It shows that approximately a third of the men switched to another sector before age 40 and remained in this new sector. Of the men's 1940 cohort, $44 \%$ remained in agriculture during the whole period, and another $20 \%$ worked in agriculture for most of the studied period but had also periods during which they did not work, or worked in other sectors.

For the men's 1960 cohort there were many similarities, but also some interesting differences. The greatest difference was naturally that the number of individuals in the cohort was much smaller: 1,824 men in the 1960 cohort compared to 3,140 men in the 1940 one (a decrease of $42 \%$ ). In other words, there was a great decrease in youths entering agriculture between 1940 and 1960.

There were also interesting differences in the trajectories of the individuals in the 1960 cohort. First and most important is that the share working in agriculture after age 25 was smaller. At age 30, the difference was only $1 \%$, but already at age 35 it had increased to 5\%, and at age 45 it was $10 \%$. At age 50, the difference decreased again to 5\%, as a large portion of the 1940 cohort exited agriculture between ages 45 and 50. This means that a larger proportion of the men exited agriculture faster in the 1960 cohort.

The men who left agriculture in the 1960 cohort mainly entered the service sector, whilst the share entering 


\section{Cohort 1940 - Males}

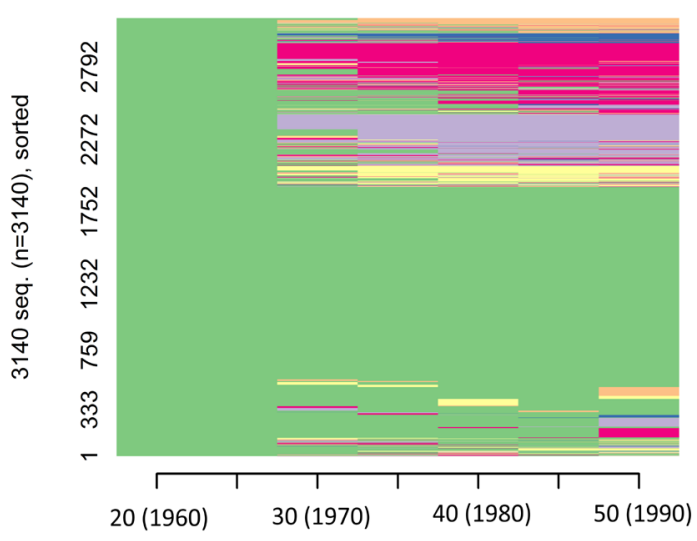

Cohort 1940 - Females

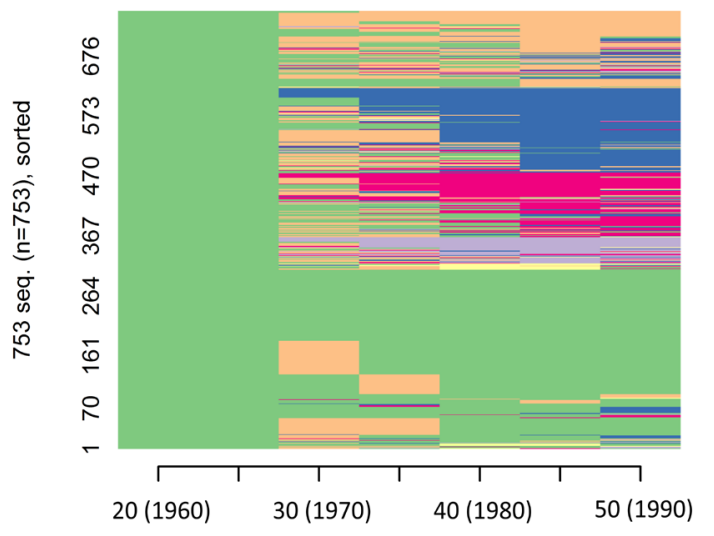

Cohort 1960 - Males

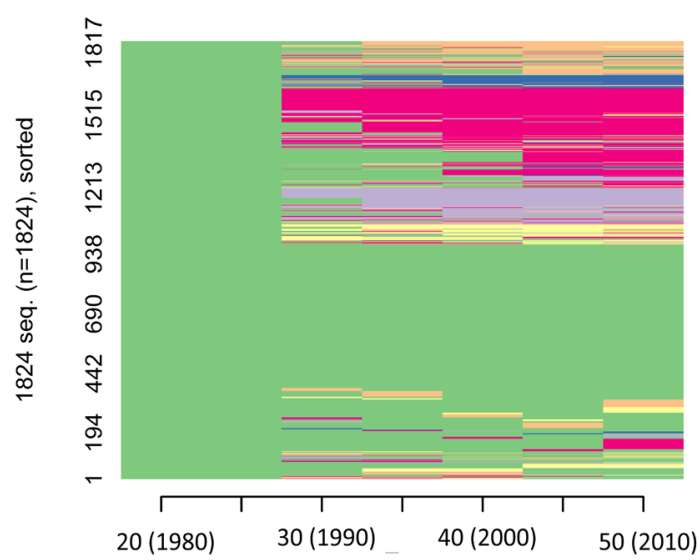

\section{Cohort 1960 - Females}

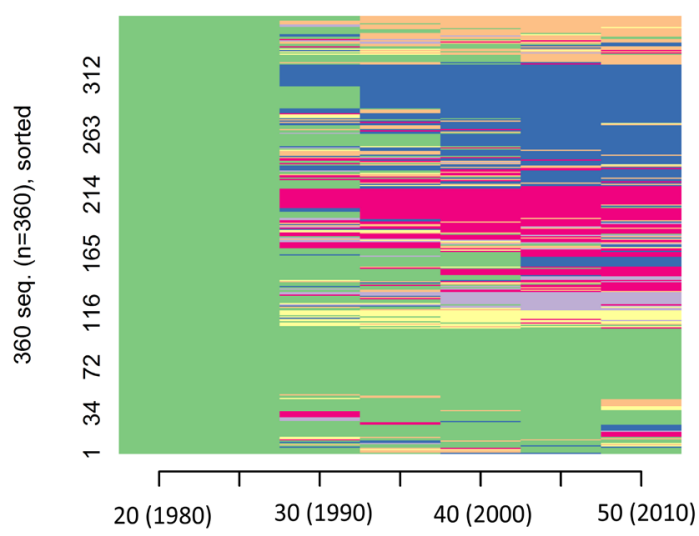

\begin{tabular}{|lll|}
\hline$\square$ Agriculture & $\square$ Not working & $\square$ Public \\
$\square$ Manufacturing & $\square$ Other natural resources & $\square$ Services \\
\hline
\end{tabular}

Fig. 1. Sequence index plot of the employment trajectories divided by cohort and sex.

manufacturing was smaller compared with the 1940 cohort. This is most likely a reflection of the general shift from manufacturing to services after 1990.

Another difference to the 1940 cohort was that a larger share in the 1960 cohort was not working. However, this increase was not primarily due to a larger group of individuals who were unemployed for longer periods; it was mainly an effect of increased turbulence in the 1960 cohort. Thus, the share who entered unemployment five years after a working period was approximately $2 \%$ higher in the 1960 cohort compared with the 1940 cohort, but the share not working who remained in unemployment five years later was 18\% lower in the 1960 cohort (Table 2). 
The diagrams on the individual trajectories for the men's cohorts (Fig. 1), shows that there is a slightly larger group in the 1960 cohort who exited agriculture relatively early and never returned (for work in another sector or no work at all). There was also a much smaller group who stayed in agriculture for the whole period (45\% in the 1940 cohort and 34\% in the 1960 cohort). On the other hand, the group who stayed in agriculture but also had shorter periods of no work, or of work in other sectors, was much larger in the 1960 cohort ( $23 \%$ in the 1940 cohort and $31 \%$ in the 1960 cohort).

One interpretation of the larger exits and the higher turbulence in the men's 1960 cohort is that it was harder for this cohort to continue working in agriculture compared with the 1940 cohort, most likely due to increased competition, rationalization, and a lack of profitability in the agricultural sector. Whilst this interpretation fits the rural restructuring framework argued for above, it must still be investigated in more detail before more definite conclusions can be drawn.

\section{Women in agriculture}

Compared with the men's cohorts, fewer women continued to work in agriculture. In the women's 1940 cohort, only $16 \%$ of the women worked in agriculture for the whole period whilst $44 \%$ in the men's 1940 cohort stayed in agriculture with no interruptions. However, another $16 \%$ of the women stayed in agriculture but were registered as 'not working' at age 30 and/or 35. During the 1970s (when the 1940 cohort was 30 years old) it was still common for women in a household to exit paid employment in order to raise children, which is the most likely explanation for the large share of women 'not working' at ages 30 and 35. It is therefore more reasonable to say that $32 \%$ of the women stayed in agriculture for the whole period, rather than $16 \%$.

Another $20 \%$ of the women's 1940 cohort continued to work in agriculture but exited for another sector after age $40(10 \%)$, or revealed a more turbulent pattern in which they had periods of working in other sectors or not working at all, only to return to agriculture (10\%). This did not differ from the men's 1940 cohort.

The women's 1940 cohort was not working to a greater extent than the men's cohort. A figure of $40 \%$ of the women at age 30 , and $30 \%$ at age 35 , was registered as 'not working' whilst the same figure for men was 3\% at both ages. After age 35 many women returned to employment and at age 40 only $12 \%$ of the women were not working. As mentioned above, the high share of women not working at ages 30 and 35 in the 1940 cohort can be ascribed to a social structure whereby women for a period exited employment to raise children, rather than 'unemployment'. But even when this is accounted for, there was still a larger share of women who exited paid employment, and $15 \%$ of the women were more or less without paid employment after age 30, compared with $3 \%$ of the men.

Of the women, 38\% exited agriculture early for long-term work in another sector. Most of them (20\%) went into the public sector, $10 \%$ of the women went into the service sector, $6 \%$ of them went into the manufacturing sector, and only a small fraction of them (2\%) worked in other natural resource sectors for a longer period. Compared with the men's 1940 cohort the women exited to other sectors to a greater extent, and were much more likely to enter the public sector than men were.

In the women's 1960 cohort, quite extensive changes had taken place. The largest change was of course that the share of women not working at ages 30 and 35 was substantially lower in the 1960 cohort compared with the 1940 one. However, in the context of agricultural employment this is not of primary importance, since it is rather part of a general change in women's working life. Furthermore, whilst the share not working at ages 30 and 35 had decreased substantially, the group who was not working for most of the period was only marginally smaller in the 1960 cohort.

More important is that the share who stayed in agriculture was substantially lower in the 1960 cohort, with only $16 \%$ of the women staying in agriculture for the whole period, whilst in the women's 1940 cohort $32 \%$ of the women stayed for the whole period (including those who did not work at age 30 and/or 35). Similar to the women's 1940 cohort, there was also a group of $20 \%$ who continued in agriculture but with a more turbulent pattern. Some worked mostly in agriculture but had periods without paid employment, others entered another job early but returned to agriculture later, and the largest group switched to another job at a later stage, primarily in the public sector. 
The group who exited agriculture early for long-term work in another sector was much larger in the 1960 cohort, at 55\% compared with 38\% in the 1940 cohort. This increase was primarily accounted for by a growth of $8 \%$ in the public sector, whilst the service sector and other natural resource sectors grew by $5 \%$ each and the manufacturing sector remained on the same level (around $5 \%$ of the women).

\section{Concluding discussion}

Comparing the labour market trajectories and income between two cohorts of agricultural workers, this study presents a detailed account of the changing conditions for men and women working in the agricultural sector. The result of the study show that fewer entered agriculture in the 1960 cohort compared with the 1940 one (42\% fewer men and 52\% fewer women). Furthermore, the individuals in the 1960 cohort exited agriculture to a greater extent and had more turbulent employment trajectories in terms of changing occupation and/or employment sector. Taken together, the employment trajectories indicate that it has become harder to work in agriculture, a reasonable result considering the demands for rationalization following the introduction of new technology and intensified global and regional competition.

Whilst the changes went in the same direction for both sexes, they were more prominent for women, which means that changes in the Swedish agricultural labour market have had a greater effect for the women in the sector. This finding is in line with previous studies from other developed countries showing that women in farm households participate to a greater extent in off-farm employment when faced with declining incomes and economic hardship (Buttel \& Gillespie 1984; Kelly \& Shortall 2002). However, it was the general development and structure of the Swedish labour market that determined where those who exited agriculture ended up. Men who exited agriculture went mainly into manufacturing and the service sector, whilst women mainly went into the public sector and the service sector, a pattern that reflects the general gender segregation of the job market. Furthermore, the number entering the service sector was substantially larger in the 1960 cohort whilst the number entering manufacturing was slightly smaller compared with the 1940 cohort. This is also a reflection of the general development in the Swedish labour market during this period, with a growing service sector and a stagnant manufacturing sector (Hedlund \& Lundholm 2015).

Therefore, for understanding the dynamics of agricultural restructuring, it is necessary to take into account not only factors within the agricultural sector but also the available opportunities in other sectors. This is also in line with the institutionalization of traditional household work in Sweden such as childcare, elderly care, cleaning, washing, et cetera. The emerging public service sector offered paid work to many individuals lacking a formal education. The service sector can be seen as a way out from an agricultural sector that over time came to be less profitable. What is harder to explain is why the female labour market seems to have been more affected by the structural change of the Swedish agricultural labour market development during the time analysed. How agricultural properties are inherited might offer an interesting line of analysis. If the property in general terms is more often owned solely by the man, this might put the woman in a much more vulnerable position. In the Swedish case, the emerging public sector offered a possibility for women to support themselves.

In a more general sense, the results offer a description of the labour market aspects of the decline and transformation of the agricultural sector on the individual level. The largest part of this decline was due to fewer entries into the sector, but the exit of farmers and agricultural workers from the sector made a significant contribution as well. Based on these results a future strand of inquiry could be to more closely examine the interplay between the 'push and pull factors' involved in the decline of agriculture; whether agriculture declined due to economic hardship in the sector or due to better opportunities in other sectors.

\section{NOTES}

1 Subsequently referred to as 'the 1940 cohort'.

2 Subsequently referred to as 'the 1960 cohort'. 


\section{ACKNOWLEDGEMENTS}

The authors would like to thank the editor and anonymous reviewers of Fennia for useful comments on the article, and The Swedish Research Council Formas for funding the research.

\section{REFERENCES}

Almstedt, Å., Brouder, P., Karlsson, S. \& Lundmark, L. (2014) Beyond post-productivism: from rural policy discourse to rural diversity. European Countryside 6(4) 297-306. https://doi. org/10.2478/euco-2014-0016

Almstedt, Å., Lundmark, L. \& Pettersson, Ö. (2015) Public spending on rural tourism in Sweden. Fennia 194(1) 18-31. https://doi.org/10.11143/46265

Alston, J.M. \& Pardey, P.G. (2014) Agriculture in the global economy. The Journal of Economic Perspectives 28(1) 121-146. http://dx.doi.org/10.1257/jep.28.1.121

Barlett, P.F., Lobao, L. \& Meyer, K. (1999) Diversity in attitudes toward farming and patterns of work among farm women: a regional comparison. Agriculture and Human Values 16(4) 343354. https://doi.org/10.1023/A:1007658532422

Boyle, P.J. \& Halfacree, K. (1998) Migration into rural areas: theories and issues. Wiley, Chichester.

Buttel, F.H. \& Gillespie, G.W. (1984) The sexual division of farm household labor: an exploratory study of the structure of on-farm and off-farm labor allocation among farm men and women. Rural Sociology 49(2) 183.

Dribe, M. \& Lundh, C. (2005) Retirement as a strategy for land transmission: a micro-study of preindustrial rural Sweden. Continuity and Change 20(2) 165-191. https://doi.org/10.1017/ S0268416005005497

Ember, C.R. (1983) The relative decline in women's contribution to agriculture with intensification. American Anthropologist 85(2) 285-304. https://doi.org/10.1525/aa.1983.85.2.02a00020

Evans, N., Morris, C. \& Winter, M. (2002) Conceptualizing agriculture: a critique of postproductivism as the new orthodoxy. Progress in Human Geography 26(3) 313-332. https://doi.org/10.1191/0309132502ph372ra

Flygare, I.A. \& Isacson, M. (2003) Jordbruket i välfärdssamhället: 1945-2000. Natur \& Kultur, Stockholm.

Friedmann, H. \& McMichael, P. (1989) Agriculture and the state system: the rise and decline of national agricultures, 1870 to the present. Sociologia Ruralis 29(2) 93-117. https://doi. org/10.1111/j.1467-9523.1989.tb00360.x

Gabadinho, A., Ritschard, G., Mueller, N.S. \& Studer, M. (2011) Analyzing and visualizing state sequences in $r$ with traminer. Journal of Statistical Software 40(4) 1-37. https://doi. org/10.18637/jss.v040.i04

Hedlund, M. \& Lundholm, E. (2015) Restructuring of rural Sweden - employment transition and out-migration of three cohorts born 1945-1980. Journal of Rural Studies 42 123-132. https:// doi.org/10.1016/j.jrurstud.2015.10.006

Hoggart, K. \& Paniagua, A. (2001) What rural restructuring? Journal of Rural Studies 17(1) 41-62. https://doi.org/10.1016/S0743-0167(00)00036-X

Ilbery, B. (1998) The geography of rural change. Longman, Harlow.

Ilbery, B. \& Bowler, I. (1998) From agricultural productivism to post-productivism. In Ilbery, B. (ed.) The geography of rural change, 57-84. Longman, Harlow.

Kelly, R. \& Shortall, S. (2002) 'Farmers' wives': women who are off-farm breadwinners and the implications for on-farm gender relations. Journal of Sociology 38(4) 327-343. https://doi. org/10.1177/144078302128756714

Lasley, P., Leistritz, F.L., Lobao, L.M. \& Meyer, K. (1995) Beyond the amber waves of grain: an examination of social and economic restructuring in the Heartland. Westview Press, Boulder.

Lobao, L. \& Meyer, K. (2001) The great agricultural transition: crisis, change, and social consequences of twentieth century us farming. Annual Review of Sociology 27(1) 103-124. https://doi.org/10.1146/annurev.soc.27.1.103

Lundmark, L., Ednarsson, M. \& Karlsson, S. (2014) International migration, self-employment and restructuring through tourism in sparsely populated areas. Scandinavian Journal of Hospitality and Tourism 14(4) 422-440. https://doi.org/10.1080/15022250.2014.967995

McCarthy, J. (2005) Rural geography: multifunctional rural geographies-reactionary or radical? Progress in Human Geography 29(6) 773. https://doi.org/10.1191/0309132505ph584pr 
Mishra, A.K. \& Goodwin, B.K. (1997) Farm income variability and the supply of off-farm labor. American Journal of Agricultural Economics 79(3) 880-887. https://doi.org/10.2307/1244429

Müller, D.K. (2010) Second homes in Sweden: between common heritage and exclusive commodity. Scandinavian Journal of Hospitality and Tourism 7(3) 193-201. https://doi. org/10.1080/15022250701300272

OECD (2006) The new rural paradigm: policies and governance. OECD, Paris.

Parson, H.E. (1999) Regional trends of agricultural restructuring in Canada. Canadian Journal of Regional Science 22(3) 343-356.

Pettersson, Ö. (2002) Socio-economic dynamics in sparse regional structures. Umeå University, Umeå.

Rosenfeld, R.A. (1985) Farm women: work farm and family in the United States. The University of North Carolina Press, Chapel Hill.

Sæther, B. (2010) Agricultural extension services and rural innovation in inner Scandinavia. Norsk Geografisk Tidsskrift-Norwegian Journal of Geography 64(1) 1-8. https://doi. org/10.1080/00291950903557647

Shaw, G. \& Williams, A.M. (1994) Critical issues in tourism: a geographical perspective. Blackwell Publishers, London.

Shucksmith, M. \& Herrmann, V. (2002) Future changes in British agriculture: projecting divergent farm household behaviour. Journal of Agricultural Economics 53(1), 37-50. https:/ldoi. org/10.1111/j.1477-9552.2002.tb00004.x

Troughton, M.J. (1986) Farming systems in the modern world. In Pacione, M. (ed.) Progress in agricultural geography, 93-123. Croom Helm, London.

Vepsäläinen, M. \& Pitkänen, K. (2010) Second home countryside. Representations of the rural in Finnish popular discourses. Journal of Rural Studies 26(2) 194-204. https://doi.org/10.1016/j. jrurstud.2009.07.002

Wilson, G.A. (2001) From productivism to post-productivism ... And back again? Exploring the (un)changed natural and mental landscapes of European agriculture. Transactions of the Institute of British Geographers 26(1) 77-102. https://doi.org/10.1111/1475-5661.00007

Woods, M. (2005) Rural geography: processes, responses, and experiences in rural restructuring. SAGE Publications, London.

Woods, M. (2010) Rural. Routledge, New York. 